Derleme Makalesi

\title{
Sağlık Perspektifinden Güzellik Salonları ve Türkiye’de Mevcut Durum Ayşegül DOĞAN ${ }^{1}$, Serap DURUKAN KÖSE ${ }^{2}$, Hatice ZABUNOĞLU ${ }^{3}$
}

\section{$\ddot{\mathbf{O} z}$}

Güzellik salonları, bünyelerinde gerçekleştirilen uygulamalar dolayısıyla insan sağlığını yakından ilgilendirmekte ve çeşitli bulaşıcı hastalıkların yayılmasına ortam oluşturarak toplum sağlı̆̆ına yönelik riskler taşımaktadır. Güzellik salonlarında gerçekleştirilmesine izin verilen uygulamalar yasal düzenlemelerle belirlenmiştir. Konu ile ilgili hukuksal çerçeve zaman içerisinde değişikliğe uğramış olmasına rağmen uygulamada bir karmaşıklığın mevcut olduğu görülmektedir. $\mathrm{Bu}$ çalışma güzellik salonlarında gerçekleştirilen uygulamalar ve yasal düzenlemeler hakkında tanımlayıcı bir çerçeve çizmeyi, bu kuruluşları sağlık perspektifinde incelemeyi ve öneriler sunmayı amaçlamaktadır. Ayrıca ulusal literatürün kısıtlı olduğu görüldüğünden, sağlık araştırmacılarının dikkatinin bu alana çekilmesi hedeflenmiştir. Çalışma, literatür taraması yöntemi kullanılan derleme bir çalışmadır. Ulusal literatür incelendiğinde yapılan çalışmaların kuaför/berber salonlarında sınırlı kaldığı, çalışanların kan yoluyla bulaşan hastalıklardan olan Hepatit B'ye karşı aşılanmanın kişilerin tercihine bırakıldığı ve dolayısıyla aşılanma oranlarının düşük olduğu görülmektedir. Çalışanlar için Hepatit B'ye karşı aşılama zorunlu hale getirilmelidir. Bu kuruluşlarda çalışanlar mesleğe başlamadan önce aldıkları eğitimlerde ve meslek içi eğitimlerle sterilizasyon, dezenfeksiyon ve bulaşıcı hastalıklar konusunda yeterli bilgi ve beceri düzeyine ulaştırılmalı, güzellik uzmanlığı eğitimlerine bir standardizasyon getirilmelidir. Güzellik salonlarında gerçekleştirilmesine izin verilen uygulamalar konusunda yeni yasal düzenlemelere ihtiyaç vardır. Bu konuda yeni bilimsel çalışmalar gerçekleştirilmesi ve uygulamaya dair eksiklikler üzerinde durulması önerilmektedir.

Anahtar kelimeler: Bulaşıcı hastalıklar, güzellik salonları, halk sağlığı

1.Öğr. Gör., Zonguldak Bülent Ecevit Üniversitesi Ahmet Erdoğan Sağlık Hizmetleri Meslek Yüksekokulu, Ağız ve Diş Sağlığı Programı, dt aysegul_dogan@hotmail.com, https://orcid.org/0000-0002-5814-6710.

2.Doç. Dr. Muğla Sitkı Koçman Üniversitesi, Sağlık Bilimleri Fakültesi, Sağlık Yönetimi Bölümü, sdurukankose@mu.edu.tr, https://orcid.org/0000-0001-5000-0664.

3.Sağlık Yönetimi Uzmanı, Adriyatik Denetim ve Belgelendirme Ltd. Şti, haticesrky@yahoo.com , https://orcid.org/0000-0002-3236-8059.

Gönderim Tarihi : 25.10.2021

Kabul Tarihi $\quad: 13.122021$

Atıfta Bulunmak İçin:

Doğan, A, Durukan Köse S.D. Zabunoğlu, H. (2021). Sağlık Perspektifinden Güzellik Salonları ve Türkiye'de Mevcut Durum, . Eurasian Journal Of Health Technology Assessment, 5(2):138-146. 


\title{
From a Health Perspective, Beauty Salons and the Current Situation in Turkey Ayşegül DOĞAN ${ }^{1}$, Serap DURUKAN KÖSE ${ }^{2}$, Hatice ZABUNOĞLU ${ }^{3}$
}

\begin{abstract}
Beauty salons are closely related to human health due to the applications performed. They threaten public health by creating an environment for the spread of various infectious diseases. Applications permitted in beauty salons are determined by legal regulations. Although the legal framework on the subject has changed over time, it seems that there is a complexity in practice. This study aims to draw a definitive framework about the practices and legal regulations carried out in beauty salons, to examine these organizations from a health perspective and to offer suggestions. In addition, as the literature seems to be very limited, it is aimed to attract the attention of health researchers to this area. This study is a review study. When the literature is examined, it is seen that the studies conducted are limited in hairdresser / barber salons and vaccination against blood-borne diseases rates are low. Mandatory primary protection methods such as vaccination against Hepatitis $B$ for employees should be implemented. Before starting the profession, the employees in these organizations should have sufficient knowledge and skills about sterilization, disinfection and infectious diseases through the trainings they received before starting their profession, and standardization should be brought to the beautician education. There is a need for new legal regulations regarding the applications allowed to be used in beauty salons. New scientific studies on this subject should be carried out and it is recommended to focus on the shortcomings of the implementation.
\end{abstract}

Key words: Infectious diseases, Beauty salons, public health

1. Lecturer Asst., Zonguldak Bulent Ecevit University Ahmet Erdogan Vocational School of Health Services, Oral and Dental Health Program, dt_aysegul_dogan@hotmail.com https://orcid.org/0000-0002-5814-6710.

2. Assoc. Dr. Muğla Sitkı Koçman University, Faculty of Health Sciences, Department of Health Management, sdurukankose@mu.edu.tr, https://orcid.org/0000-0001-5000-0664.

3. Health Management Specialist, Adriatic Audit and Certification Ltd. Sti, haticesrky@yahoo.com , https://orcid.org/0000-0002-3236-8059.

Received : 25.10 .2021

Accepted : 13.12.2021

Cite This Paper:

Doğan, A, Durukan Köse S.D. Zabunoğlu, H. (2021). From a Health Perspective, Beauty Salons and the Current Situation in Turkey, Eurasian Journal Of Health Technology Assessment, 5(2): 138-146. 


\section{Giriș}

Güzellik salonları, bünyelerinde gerçekleştirilen uygulamalar dolayısıyla insan sağlı̆̆ını yakından ilgilendiren kuruluşlardır. Bu kuruluşlarda saç bakımı, tırnak bakımı, cilt bakımı, epilasyon gibi çok çeşitli türde uygulama gerçekleştirilmektedir. Uygulamaların türü ve kullanılan aletler ile cihazlar çeşitli biyolojik tehlikelere zemin oluşturmaktadır. $\mathrm{Bu}$ kuruluşlardan pek çok bulaşıcı hastalığın kişilere geçtiği ve toplum sağlığı için ciddi riskler oluşturabileceği ileri sürülmüştür (Deghani vd., 2016). Yapılan işlemlerin bir çoğu deri bütünlügünü bozan, kan gibi vücut sıvilarıyla aletlerin kontamine olmasına neden olan özelliktedir. Güzellik salonlarında hijyen kurallarına uyulmaması nedeniyle Hepatit B, Hepatit $\mathrm{C}$ gibi kan yoluyla bulaşan hastalıklar, deri ve göz hastalıkları, mantar enfeksiyonları ve saç biti gibi parazitlerin bulaşı söz konusu olmaktadır (Stanley vd., 2015). Ayrıca kullanılan malzemelerin bazıları asitler gibi tehlikeli kimyasallar içermektedir (Behravan vd., 2005). Faaliyet kapsamı ve barındırdığı riskler itibariyle güzellik salonlarının sağlık perspektifinden incelenmesi önem arz etmektedir. Bu konudaki ulusal literatürün kısıtlı olduğu söylenebilir. Bu çalışmanın amacı güzellik salonlarının sağlık perspektifinden ele alınması gerekliliğine dikkat çekmektir. Ulusal literatürde yer alan çalışmaların güzellik salonu çalışanlarının hijyen ve bulaşıcı hastalıklar konusundaki bilgi düzeylerinin değerlendirilmesi üzerine yoğunlaştıkları görülmektedir (Boztaş, 2006; Vurucuoğlu vd., 2018; Sözen vd., 2018). Oysa ki bu durum güzellik salonlarının toplum sağlığı için tehlike oluşturma nedenlerinin sadece bir yönünü oluşturmaktadır. Bu kuruluşlarda hijyen kurallarına uyulmaması dışında tıbbi cihaz statüsünde bulunan ve sadece sağlık personelinin kullanım yetkisinde olan bazı cihazların meydana getirebileceği zararlar da toplum sağlığı için önemli riskle barındırmaktadır. Söz konusu cihazların yetkisi olmayan güzellik salonu çalışanları tarafından kullanılması çeşitli davalara konu olmuştur (Kar vd., 2016). Bu nedenle güzellik salonları sağllk perspektifinden değerlendirilirken mevzuatın da dikkate alınması önem arz etmektedir. Güzellik salonlarında uygulanması gereken sterilizasyon, dezenfeksiyon yöntemleri personelin bilinç düzeyi ve dolayısıyla eğitimi ile bağlantılıdır (Sözen vd., 2018). Yöntemlerin etkin kullanımı çeşitli denetimler ve yasal düzenlemelerle sağlanabilir. Bu çalışmada Türkiye'deki mevcut işleyişi ve mevzuatı da ortaya koyarak tanımlayıcı bir çerçeve çizilmesi ve konuya ilişkin öneriler sunulmasi hedeflenmektedir.

\section{Güzellik Salonlarının Sağlık Kavramıyla İlişkisi}

Bir kavram olarak sağlık, Dünya Sağlık Örgütü tarafından "Yalnızca hastalık veya sakatlığın olmaması durumu değil, fiziksel, sosyal ve ruhsal refah durumu" şeklinde tanımlanmıştır (WHO, 1946). Ruhsal sağlık açısından bireyin bedeninden hoşnut olması önemlidir. Beden imajından memnun olmama hali depresyona yol açabilmekte ve depresyon da beden algısını bozabilmektedir. Kendine güven ve çekicilikle ilişkilendirilen beden imajı, tüm yaşam boyunca, benlik değeri ve ruhsal sağlığın önemli bir yönünü meydana getirmektedir (Çelen, 2007). Günümüzde medyanın da dahil olması ile güzel ve estetik olma kriterleri devamlı farklılaştığı için bireylerin kendileriyle ilgili beden algıları sürekli değişmektedir. Ayrıca günümüz bakış açısına göre yaşamın doğal bir süreci olan "yaşlanma" tedavi edilmesi ve durdurulması gereken bir problem haline gelmiştir. İstenen genç ve estetik olarak kabul edilebilir görüntüye sahip olmak adına bireyler cerrahi ve cerrahi olmayan bazı uygulamalara başvurmaktadır (Sezgin, 2015). Böylece kozmetik uygulamalara başvurularak beden görünümünün iyileştirilmesi ruhsal sağlığı da iyileştirmektedir (Jones, 2008; Teague vd, 2011; Merianos vd., 2013).

Son yıllarda güzellik ve estetik sektörü en hızlı gelişen sektörlerden biri olmuştur. Bununla birlikte, çeşitli uygulamaların yapıldığı güzellik salonları hijyen kurallarının göz ardı edilmesi, kesici aletlerin enfeksiyon riski yaratması dolayısıyla hem çalışanlar hem de başvuranlar açısından pek çok sağlık riskini beraberinde getirmektedir (Canyılmaz, 2009). Güzellik salonlarında kullanılan kesici-delici aletler/cihazlar ve deri bütünlüğünü bozan cilt bakımı, vücut 
bakımı, epilasyon/depilasyon gibi uygulamalar neticesinde bulaşıcı kan ve deri hastalıklarının yayılmasına ortam oluşturduğu bildirilmiştir (Boztaş, 2006; Edward vd., 2015, Dehghani vd., 2016, Vurucuoğlu vd., 2018, Wazir vd., 2013).

Çeşitli ülkelerde bu merkezlerden, dünyada erken ölüm sebebi olarak gösterilen ilk beş hastalık arasında olduğu bilinen viral hepatit türlerinden HCV (Hepatit C Virüsü) ve HBV(Hepatit B Virüsü) bulaşı rapor edilmiştir (Janjua ve Nizamy, 2004). Mancini ve arkadaşları (2018), Roma'daki güzellik salonlarında karşılaşılan mikrobiyolojik hastalıkları araştırdıkları çalışmalarında salonların \%89,2'sinde mantar enfeksiyonları ve dermatitle karşılaşıldığını, çalışma kapsamında değerlendirilen güzellik salonlarının sadece \%31,7'sinde mikrobiyolojik risk önleme yöntemleri kullanıldığını ortaya koymuşlardır. Huijsdens ve arkadaşları (2008), Hollanda'da bir güzellik salonundan kaynaklı metisilin dirençli Staphylococcus aureus (MRSA) salgını olduğunu rapor etmişlerdir. S. aureus, hem yüzeyel enfekeksiyonlara hem de yaşamı tehdit edecek kadar ciddi enfeksiyonlara yol açabilen bir bakteridir (Huijsdens vd., 2008). Nijerya'da yapılan bir çalışmada güzellik salonlarından S. aureus, S. epidermidis, Enterococcus türleri, Aspergillus türleri, Penicillium türleri ${ }^{1}$ gibi patojenlerin izole edildiği gösterilmiş ve bölgede enfeksiyonların yayılımında güzellik salonlarının rolü olabileceği üzerinde durulmuştur (Enemour, 2013). Güzellik salonlarında kullanılan firçalar, taraklar, tırnak bakım malzemeleri, krem ve losyonlar gibi ürünlerin bu mikroorganizmaların çoğalması için uygun ortamlar olduğu bildirilmiştir (Alharbi ve Alhashim, 2021). Dehghani ve arkadaşlarının (2016) yaptığı çalışmada 220 güzellik salonunun yasal sağlık prosedürlerine uygunluğu değerlendirilmiş ve sadece $\% 44,5$ 'inin gerekli şartları sağladığı görülmüştür. Güzellik salonlarının bünyelerinde sunulan hizmetler, bulaşıcı hastalıklar açısından risk oluşturarak insan sağlığını birebir ilgilendirmektedir. $\mathrm{Bu}$ nedenle güzellik salonlarının toplum sağlı̆̆ı ile yakından ilişkili kuruluşlar olduğu söylenebilir. Bu kuruluşlarda enfeksiyon kontrol yöntemlerinin uygulanması ve gerekli hijyen tedbirlerinin alınması toplum sağlığı açısından önem taşımaktadır (Alharbi ve Alhashim, 2021; Sekula vd., 2002).

\section{Türkiye'de Güzellik Salonlarının Sağlıkla İlişkili Durumu ve Mevzuat}

Türkiye'de güzellik ve estetik sektörünün hızla gelişmekle birlikte, güzellik salonları ve kuaförlerin sağlık açısından değerlendirildiği literatürün sınırlı olduğu görülmektedir.

\subsection{Türkiye’de Güzellik Salonlarının Sağlık Perspektifinden Mevcut Durumu}

Yapılan çalışmaların güzellik salonu çalışanlarının hijyen ve bulaşıcı hastalıklar konusundaki bilgi düzeyleri üzerine yoğunlaştığı dikkat çekmektedir. Boztaş ve arkadaşları (2006), yaptıkları kesitsel çalışmada kuaför ve güzellik salonu çalışanlarının sadece \%58'inin eldiven kullandığını, çalışanların \%13'ünün ise kan yolu ile bulaşan hastalıklara karşı herhangi bir tedbir almadığını belirtmişlerdir. Vurucuoğlu ve arkadaşları (2018), çalışmalarında güzellik salonu ve kuaför çalışanlarının Hepatit C ve AIDS gibi ölümcül hastalıkların bulaşıcılığı konusunda çok yetersiz bilgiye sahip olduğunu, katılımcıların sadece \%33'ünün hepatit aşısı yaptırmış olduğunu bildirmişler ve çalışanların zorunlu denetim eksikliklerinden bahsettiğine dikkat çekmişlerdir. Benzer şekilde kuaför ve güzellik salonlarında çalışanların hijyen ve bulaşıcı hastalıklara ilişkin bilgi düzeylerinin değerlendirildiği araştırmalarda çalışanların bu konuda bilgi düzeylerinin yetersiz olduğu sonucuna varılmıştır (Sözen vd., 2018, Özaras vd., 2013). Togan ve arkadaşları (2014) güzellik uzmanlarının eğitim seviyesinin yükseltilmesinin önemine dikkat çekmişler, güzellik salonlarında denetim faaliyetlerinin arttırılması gerektiğini bildirmişlerdir.

Türkiye'de güzellik ve estetik sektörünün hızla geliştiği görülmektedir. Uluslararası Estetik Plastik Cerrahlar Birliği (ISAPS)'nin verilerine göre 2011-2016 yılları arasında Türkiye'de

\footnotetext{
${ }^{1}$ Akciğer ve deri enfeksiyonları gibi durumlara neden olan bazı mikroorganizmalar
} 
cerrahi olmayan operasyon sayısının \%199 oranında arttığ1 görülmüştür. En sık uygulanan cerrahi olmayan operasyonlar botoks, dolgu ve epilasyon olarak bildirilmiştir. ISAPS 2018 Uluslararası Estetik/kozmetik Prosedürler Anketi sonuçlarına göre Türkiye, uygulanan cerrahi olmayan güzellik operasyonları sayısına göre dünya ülkeleri arasında 11. sırada yer almaktadır (ISAPS, 2018).

Cerrahi olmayan bu tür operasyonlar hekimlere ait klinikler, güzellik merkezleri ve güzellik salonlarında uygulanmaktadır. Ülkemizde güzellik salonlarını konu alan yasal mevzuatın düzenlenme sürecinin karmaşık olduğu görülmektedir. Bundan sonraki bölümde tarihsel olarak bu mevzuatların düzenlenme sürecine yer verilecektir.

\subsection{Güzellik Salonları Mevzuatı}

Güzellik uzmanı, “iş sağllğı ve güvenliği, çevre koruma ve kalite gerekliliklerine uygun olarak iş organizasyonu yapan, ön hazırlık yaparak kullanılacak cilt/vücut bakım ürününü, yöntemi ve cihazını belirleyen, cilde temizleyici kozmetik ürün, peeling, buhar uygulayan, ciltte gözenek temizliği yapan, tonik, ampul/serum, nemlendirici uygulayan, vücut bakımı öncesinde kontrol/ölçüm yapan, cihazla vücut bakımı ve bakım masajı yapan, epilasyon/depilasyon yapılacak bölge ve tekniği belirleyen, iğneli epilasyon, foto epilasyon, depilasyon ve ağda yapan, kaşı şekillendiren, makyaj türünü ve kullanılacak kozmetik ürünleri belirleyerek standart makyaj uygulamaları yapan ve mesleki gelişim faaliyetlerine katılan nitelikli kişi” olarak tanımlanmaktadır.(Mesleki Yeterlilik Kurumu, 2021).

Türkiye'de güzellik salonlarında görev yapmak üzere yetiştirilen güzellik uzmanlarının eğitim sürecine bakılacak olursa, Milli Eğitim Bakanlığı tarafından eğitim içeriği belirlenmiş olan çeşitli kurslar ile üniversitelerin saç bakımı ve güzellik hizmetleri ve dengi programlarından mezun olan kişilerin güzellik uzmanı olmaya hak kazandığı görülmektedir (Saracaloğlu ve Bayık, 2017). 1739 sayılı Milli Eğitim Temel Kanunu, 5580 Sayılı Özel Öğretim Kurumları Kanunu, Özel Öğretim Kurumları Yönetmeliği, 13UMS0287-4 Referans Kodlu Güzellik Uzmanı Ulusal Meslek Standardı, Talim ve Terbiye Kurulu Başkanlığının 05/10/2018 tarihli ve 130 sayılı Kararı ile onaylanan Özel Kurslar Çerçeve Programı esas alınarak hazırlanan kurs programı sonucunda kursiyerlerden beklenen yetkinlikler; iş organizasyonu yapmaları, iş sağlığı ve güvenliği (İSG) faaliyetlerini yürütmeleri, kalite yönetim sistemini uygulamaları, cilt ve vücut bakımı yapmaları, epilasyon/depilasyon yapmaları, makyaj yapmaları, mesleki gelişim faaliyetlerine katılmaya istekli olmaları" şeklinde belirtilmiştir (Milli Eğitim Bakanlı̆̆g, 2020). Güzellik uzmanlığı mesleğine yönelik özel düzenlemeler; 2872 sayılı Çevre Kanunu ve yürürlükteki alt mevzuatı, 4857 sayılı İş Kanunu ve yürürlükteki alt mevzuatı ile 6331 sayılı İş Sağlığı ve Güvenliği Kanunu ve yürürlükteki alt mevzuatıdır (Mesleki Yeterlilik Kurumu, 2021).

Güzellik salonlarını konu alan ilk yasal düzenleme 12/5/2003 tarih ve 23988 sayılı Resmi Gazetede yayınlanan “Güzellik ve Estetik Amaçlı Sağlık Kuruluşları Hakkındaki Yönetmelik”tir (Güzellik ve Estetik Amaçlı Sağlık Kuruluşları Hakkındaki Yönetmelik, 2003). Güzellik salonlarının çalışma şartları 10/08/2005 tarihli ve 2005/9207 sayılı Bakanlar Kurulu kararı ile yürürlüğe koyulan "İş yeri Açma ve Çalışma Ruhsatlarına İlişkin Yönetmelik" ve 15/2/2008 tarihinde resmi gazetede yayınlanarak yürürlüğe koyulan "Ayakta Teşhis ve Tedavi Yapılan Özel Sağlık Kuruluşları Hakkında Yönetmelik” ile düzenlenmiştir. Önceki yönetmelikte güzellik salonları "gerçek veya tüzel kişiler tarafından bir güzellik uzmanı sorumluluğunda açılan ve bünyesinde bulundurdukları birimlere göre gerekli asgari standart donanım ve personel desteği ile güzellik ve estetik amaçlı olarak faaliyet gösteren özel sağlık kuruluşları" olarak tanımlanmıştır. Fakat 15/2/2008 tarihinde Resmi Gazete'de yayınlanarak yürürlüğe koyulan 
“Ayakta Teşhis ve Tedavi Yapılan Özel Sağlık Kuruluşları Hakkında Yönetmeliğe” göre güzellik salonları sağlık kuruluşu statüsünden çıkarılmış ve ruhsatlandırılmaları belediyelere devredilmiştir.

İş Yeri Açma ve Çalışma Ruhsatlarına İlişkin Yönetmelikte 29/6/2010 tarih ve 2010/671 sayılı Bakanlar Kurulu kararı ile yönetmeliğe eklenen (j) bölümünde güzellik salonlarında yapılabilecek uygulamalar tarif edilmiştir. Bu uygulamalar; "cilt bakımı, makyaj uygulamaları, kozmetik amaçlı kaş şekillendirmeleri, ipek kirpik uygulamaları, ağda ve epilasyon uygulamaları, protez tırnak, tırnak süsleme, manikür-pedikür, selülit giderici uygulamalar, lenf drenaj uygulaması, elektrik akım sistemleriyle bakım, lifting, oksijen ve ozon bakımı, solaryum, kaş ve kirpik şekillendirme işlemleri” olarak bildirilmiştir (Resmi Gazete, 2020).

Güzellik salonlarında en sık uygulanan işlemlerden biri olan lazer epilasyonu, sağlik kurumlarının özellikle dermatoloji kliniklerinde tıbbi endikasyon içerisinde tedavi amacıyla, hekimin ya da hekim gözetiminde sağllk personelinin uygulayabildiği gibi güzellik/estetik merkezlerinde "sağlık bilgisi ve hatta uygulama yetkisi olmayan kişiler tarafindan" da uygulanmakta olduğu görülmektedir (Kar vd., 2016). Lazer epilasyon işlemlerine ait icra yetkisi hususunda yasal süreç karmaşık şekilde işlemiştir. Nihayetinde, uygulayıcıların politika yapımı sürecine olası müdahaleleri vb. nedenlerle Ayakta Teşhis ve Tedavi Yapılan Özel Sağlık Kuruluşları Hakkında Yönetmelikte lazer epilasyon uygulamalarına ait icra yetkisinin tabip ve uzman tabiplere bırakılmasına hükmolunmuştur. Ancak 2017/10085 sayılı Bakanlar Kurulu kararına istinaden 30 Mart 2017 tarih ve 30023 sayılı Resmi Gazetede yayımlanarak yürürlüğe giren "İş yeri Açma ve Çalışma Ruhsatlarına İlişskin Yönetmelikte Değişiklik Yapılmasına Dair Yönetmelik" ile beraber güzellik salonlarında lazer epilasyon yöntemleri hariç, "tıbbi cihaz kapsamına girmeyen cihazlarla epilasyon ve depilasyon işlemlerinin güzellik uzmanlarınca yapılabileceği” bildirilmiştir. Lazer cihazlarının güzellik uzmanları tarafından kullanılmasının neticelerine dikkat çeken bir çalışmada Kar ve arkadaşları (2016), lazer epilasyona bağlı oluşan cilt lezyonlarını malpraktis açısından değerlendirmişler ve adli tıp kurumuna yönlendirilen 14 vakanın 12'sinin güzellik salonlarında güzellik uzmanları tarafından gerçekleştirildiğini rapor etmişlerdir.

Günümüzde güzellik salonlarında gerçekleştirilen popüler uygulamalardan biri de dermapen (mikroiğneleme) işlemidir. Bu işlem akne lekelerinin, cilt tonu eşitsizliklerinin, gözenek problemlerinin düzeltilmesi, cerrahi skar dokusunun eliminasyonu ve transdermal ilaç uygulaması gibi amaçlarla uygulanan cilt içerisine minimal invaziv girişimle mikro iğnelerin tatbik edilmesi ve cildin yenilenme sürecinin uyarılması şeklinde gerçekleşmektedir (Alster ve Graham, 2017). Burada dikkat çekici olan nokta, güzellik salonlarında güzellik uzmanlarınca uygulandığı görülen mikroiğneleme için kullanılan dermapen ve dermoroller gibi cihazların Tıbbi Cihaz Yönetmeliği kapsamında yer alması ve yasal kullanım yetkisinin sağlık personeline ait olmasıdır. Ne var ki güzellik salonlarının internet siteleri, sosyal medya hesapları ve broşürlerinden görüldüğü üzere mikroiğneleme uygulaması güzellik salonlarının birçoğunda mevcuttur.

Diğer taraftan, ülkemizde uyumlaştırma çalışmaları tamamlanarak 02.06.2021 tarihli ve 31499 (Mükerrer) sayılı Resmi Gazete'de ulusal mevzuat olarak yayımlanan Avrupa Birliği'nin yeni tıbbi cihaz tüzüğü (05.05.2017 tarihli ve (AB) 2017/745 sayılı Tıbbi Cihaz Regülasyonu) ile tıbbi bir kullanım amacı olmayan ancak fonksiyonu ve risk profili itibariyle tıbbi cihazlara benzer bazı ürün grupları söz konusu regülasyon kapsamına alınmıştır.

Cilt yenileme, dövme silme veya tüy alma ya da diğer cilt uygulamalarına yönelik lazerler ve yoğun atımlı 1şık (IPL) ekipmanı gibi, monokromatik ve geniş spektrumda, eş fazlı ve eş fazlı 
olmayan kaynaklar dâhil, insan vücudu üzerinde kullanılması amaçlanan yüksek yoğunluklu elektromanyetik radyasyon (örneğin, kızıl-ötesi/infrared, görünür 1 şık ve ultraviyole) yayan ekipmanlar, söz konusu Tıbbi Cihaz Yönetmeliği kapsamına alınan ürünler arasında yer almaktadır. Böylelikle estetik amaçl, ancak risk profili yüksek olan lazer epilasyon ve benzeri cihazlar, tıbbi cihaz mevzuatına uygun şekilde piyasaya arz edilmek durumundadır(Resmi Gazete, 2021).

Estetik amaçlı kullanılan cihaz ve ekipmanların tabi olduğu mevzuatlarda, söz konusu ürünlerin karşılaması gereken tüm yasal gereklilikler tanımlanmaktadır. Bu cihazları kullanma/uygulama yetkisi ise ilgili mevzuat kapsamında belirli meslek gruplarına ve kuruluşlara verilmiştir. Ancak bu yetkinin yasal çerçeve dışında kullanımı, halk sağlığı açısından büyük bir risk oluşturmaktadır.

\section{Sonuç ve Öneriler}

Güzellik salonları insan sağlığını birebir ilgilendiren uygulamaları ve bulaşıcı hastalıklara transfer ortamı oluşturmaları dolayısıyla toplum sağlı̆g için potansiyel riskler barındırmaktadır. Güzellik uzmanlığı, dünyada olduğu gibi ülkemizde de yeni tanımlanan meslekler arasındadır. Sektör çalışanlarının eğitim alt yapılarındaki farklılıklar uygulamaya yansımaktadır. Yapılan çalışmalar güzellik uzmanlarının bulaşıcı hastalıklar ve hijyen konularında hem bilgi hem de uygulama eksikliklerinin olduğuna dikkat çekmektedir. Türkiye'de çeşitli uygulamalar açısından hukuksal çerçevenin zaman içerisinde değiştiği görülmektedir. Bazı uygulamaların tıbbi prosedürlere sadık kalınarak yapılması gerekmekte, ancak mevcut durumda bu konuda karmaşık bir işleyişin olduğu dikkat çekmektedir. Konuya getirilebilecek öneriler aşağıda sıralanmıştır:

Uygulayıcılara yönelik öneriler;

- Güzellik salonlarının insan ve toplum sağlığını etkileyen kuruluşlar olduğu unutulmamalı, eğitimler bu nokta göz önünde bulundurularak gerçekleştirilmelidir.

- Güzellik salonlarında çalışanlar sterilizasyon ve dezenfeksiyon kurallarına uygun şekilde hareket etmelidir.

Politika yapıcılara yönelik öneriler;

- Çalışanlar işe başlamadan önce aldıkları eğitimlerde ve meslek içi eğitimlerle sterilizasyon, dezenfeksiyon ve bulaşıcı hastalıklar konusunda yeterli bilgi ve beceri düzeyine ulaştırılmalı, güzellik uzmanlığı eğitimlerine bir standardizasyon getirilmelidir.

- Denetimler, iyileştirmeye katkı sağlamalı; yaptırımlar, aykırılıkların tekrarlanmasını önleyecek şekilde uygulanmalıdır.

- Hepatit B'ye karşı aşılanma tercihinin kişilere bırakıldığı ve dolayısıyla oranlarının düşük olduğu görülmektedir. Güzellik salonu çalışanları için Hepatit B'ye karşı aşılama zorunlu hale getirilmelidir.

- Güzellik salonlarında gerçekleştirilmesine izin verilen uygulamalar konusunda deneyimler ve gelişmeler doğrultusunda yeni yasal düzenlemelere ihtiyaç vardır.

Araştırmacılara yönelik öneriler;

- İleride yapılacak araştırmalar için, güzellik salonlarını sağlık perspektifinden ele alan yeni bilimsel çalışmaların planlanması ve uygulamaya dair eksiklikler üzerinde durulması önerilmektedir.

- Güzellik uzmanları Milli Eğitim Bakanlığı tarafından eğitim içeriği belirlenmiş olan çeşitli kurslardan ve üniversitelerin Saç Bakımı ve Güzellik Hizmetleri Programlarından mezun olarak görev yapmaya hak kazanmaktadır. Eğitim alt yapısındaki bu farkın mesleki uygulamalara ne şekilde yansıdığg konusunda ileriye yönelik çalışmalar planlanabilir. 


\section{Kaynakça}

1. Alharbi, N.M. ve Alhashim, H. M. (2021). Beauty Salons are Key Potential Sources of Disease Spread. Infection and Drug Resistance. 14, 1247-1253.

2. Alster, T., Graham, P.(2017). Microneedling: A review and practical guide. Dermatologic Surgery. 44(3), $1-8$.

3. Behravan, J., Bazzaz, F., Malaekeh, P. (2005). Survey of bacteriological contamination of cosmetic creams in Iran. Int J Dermatol. 44 (6), 482-485.

4. Boztaş, G., Çilingiroğlu, N., Özvarış, Ş.B., Karaöz, A., Karataş, F., Kara, G., Orhan, N., Taşoğlu, Ö., Mümüşoğlu, S., Güzel, T. (2006). Ankara İlinin Bir Semtinde Bulunan Kuaför ve Güzellik Salonlarında Çalışan Kişilerin Kan Yoluyla Bulaşan Hastalıklar Konusunda Bazı Görüş ve Uygulamaları. Hemşirelik Yüksekokulu Derg., 60-68

5. Canyılmaz, D.(2009). Berber ve Kuaför Hizmetlerinde DAS Uygulamaları. 6. Ulusal Sterilizasyon Dezenfeksiyon Kongresi Antalya, 407-416.

6. Çelen, N. (2007), Ergenlik ve Genç Yetişkinlik. Papatya Yayıncılık, İstanbul.

7. Dehghani, R., Mesgari L, Moghadam MF, Rezaian F.(2017). Studying the environmental health status of beauty salons of Kashan. International Journal of Epidemiologic Research, 4(1), 24-30.

8. Edward, S.M., Megantara, I., Dwiyana, RF. (2015) Detection of Fungi in Hair-brushes in Beauty Salons at Jatinangor. Althea Med J., 2 (4), 516-520.

9. Enemour S. (2013). Evaluation of bacterial and fungal contamination in hairdressing and beauty salons. African Journal Of Microbiology Research, 7(14), 1222-1225.

10. Huijsdens, X.W., Janssen M, Renders NH, Leenders A, Van Wiik P.(2008).'Methicillin-resistant Staphylococcus aureus in a beauty salon, The Netherlands". Emerging Infectious Diseases, 14(11), 17971799.

11. Janjua, N.Z, Nizamy MA.(2004). Knowledge and practices of barbers about hepatitis B and C transmission in Rawalpindi and Islamabad. J Pak Med Assoc., 54(3), 116-9.

12. Jones, M. (2008). Skintight: An anatomy of cosmetic surgery. London, UK: Bloomsbury Academic.

13. Kar, H, Dokgöz H, Gamsız Bilgin N, Albayrak B,Kayan T.İ.(2016). Lazer Eplasyona Bağlı Cilt Lezyonlarının Malpraktis Açısından Değerlendirilmesi. Adli Tıp Bülteni, 21(3), 153-158.

14. Mancini, L., Figliomeni, M., Puccinelli, C., Romanelli, C., Volpi, F. (2018). A descriptive study on microbiological risk in beauty salons. Microchemical Journal, 136, 223-226.

15. Merianos, A, Vidourek R.A., King K. (2013). Medicalization of Female Beauty: A content analysis of cosmetic procedures. Qual Rep, 18(46), 1-14.

16. Özaras, F., Çalışkan, E., Öztürk, C.E. (2013). Bayan kuaför ve güzellik merkezi çalışanlarının hijyenbulaşıcı hastalıklar konularında bilgi düzeylerinin değerlendirilmesi ve kan yoluyla bulaşan hastalıklar ile Onikomikoz yönünden incelenmesi. Viral Hepatit Dergisi, 19(3), 115-118.

17. Saracaloğlu, S. Ve Bayık S. (2017). Meslek Yüksek Okulu Saç Bakım ve Güzellik Hizmetleri Önlisans Programı İhtiyaçlarının Değerlendirilmesi. Kesit Akademi Derg, 3(11), 693-711.

18. Sekula SA, Havel J, Otillar LJ (2002). Nail salons can be risky business. Arch. Dermatol. 138, 414-415.

19. Sezgin, D. (2015). Toplumsal Cinsiyet Perspektifinde Sağlık ve Tıbbileştirme. Sosyoloji Araştırmaları Dergisi. 18(1), 153-186.

20. Sözen, G., Karabay, O, Karabel M.P., Keskin M,Karahan H, İnci M.B., Öğütlü A, Güçlü E, Ekerbiçer H.Ç.(2018). "Güzellik uzmanlarının mesleki uyg. İle ilişkili olabilecek bulaşıcı hastalık ve hijyen konularındaki bilgi, tutum ve davranışlarının değerlendirilmesi”. Sakarya Tıp Derg., 8(1), 70-79.

21. Stanley MC, Ifeanyi OE, Kingsley O.(2015). Evaluation of microbial contamination of tools used in hair dressing salons in Michael Okpara University of Agriculture, Umudike, Abia State. Curr Allergy Asthma Rep. 15,1 .

22. Teague, M. L., Mackenzie, S. L. C., \& Rosenthal, D. M. (2011). Your health today (3rd ed.). New York, NY: McGraw-Hill.

23. Togan, T., Turan, H., Arslan, H. (2014). "Manisa il merkezinde berber, kuaför ve güzellik salonu çalışanlarının hepatit konusundaki bilgi düzeyi, tutum ve davranışları" .ANKEM Dergisi, 28(2), 50-57.

24. Vurucuoğlu, A., Özdemir Güngör, D., Camuz Berber, İ., Kıdak, L.B. (2018). "Kuaför ve güzellik salonu çalışanlarının bulaşıcı hastalıklar konjusunda bilgi düzeyleri ve uygulanan korunma yöntemleri". Izmir Democracy University Health Sciences Journal, 1(1), 27-38.

25. ISAPS Global Survey Results 2018 https://www.isaps.org/medical-professionals/isaps-global-statistics/ (Erişim Tarihi: 10.05.2020).

26. Güzellik ve Estetik Amaçlı Sağlık Kuruluşları Hakkında Yönetmelik http://www.resmigazete.gov.tr/eskiler/2003/05/20030512.htm (Erişim Tarihi:04.08.2021). 
27. Resmi Gazete (2005), İşyeri Açma ve Çalışma Ruhsatlarına İlişkin Yönetmelikte Değişiklik Yapılmasına Dair Yönetmelik http://www.resmigazete.gov.tr/eskiler/2 (Erişim Tarihi: 15.07.2021).

28. Resmi Gazete (2008), Ayaktan Teşhis ve Tedavi Yapılan Özel Sağlık Kuruluşları Hakkında Yönetmelik, http://www.resmigazete.gov.tr/eskiler/2008/02/20080215-4.htm (Erişim Tarihi:06.09.2021).

29. Mesleki Yeterlilik Kurumu (2021), https://portal.myk.gov.tr/index.php?fileName=13UMS02874\%20Rev\%2001\%20G\%C3\%BCzellik\%20Uzman\%C4\%B1\&dl=Meslek Standartlari/5606/SON_TAS LAK_PDF_20210820_163732.pdf (Erişim Tarihi: 26.11.2021).

30. Milli Eğitim Bakanlığı (2021), M.E.B. Güzellik uzmanlığı kursu programı https://ookgm.meb.gov.tr/meb_iys_dosyalar/2019_05/13122254_Guzellik_UzmanY_Kurs_ProgramY.p df (Erişim Tarihi: 07.09.2021).

31. M. S. Wazir, S. Mehmood, A. Ahmed, and H. R. Jadoon, (2013) Awareness among barbers about health hazards associatedwith their profession, Journal of Ayub Medical College, Abbottabad: JAMC, 20(2), 3538.

32. World Health Organisation (1946). Constitution. Geneva: World Health Organisation. 